\title{
Improvement of Learning Outcomes Inorganic Chemistry Through Cooperative Learning Approach Types Student Teams- Achievement Divisions with The Help Of Molymod Props
}

\author{
Reni Banowati Istiningrum ${ }^{a, *}$, Bayu Wiyantoko ${ }^{a}$ \\ aDiploma of Analytical Chemistry, Islamic University of Indonesia \\ *Corresponding author: reni_banowati@uii.ac.id
}

\begin{abstract}
This study aims to study the application of STAD type cooperative learning in the course of Inorganic Chemistry combined with the use of Molymod props. The purpose of this study is to determine whether there is the influence of the application of STAD strategy and props Molymod to students' understanding on the subject of Inorganic Chemistry. Implementation of learning is done in two cycles, each cycle includes group learning outside the classroom, material confirmation by the lecturer, working on using the worksheet, and quiz. The data obtained were processed to see the development of each group from the value of the worksheet 1 to the worksheet 9 . The group's developmental value was also measured using quizzes performed twice individually. Student attitudes toward STAD and Molymod use were measured using a behavioral scale questionnaire. Based on the assessment of group development, almost all groups showed an increase in group progress from worksheet 1 to worksheet 9 . However, the group development value between worksheets and quizzes dropped dramatically. There is no influence of student attitude toward STAD strategy with material understanding. However, the use of molymod influences strong enough to the understanding of student materials. As many as $50 \%$ of students get a minimum score of $B$.
\end{abstract}

Keywords: STAD, cooperative learning, learning outcomes, inorganic chemistry, molymod props

\section{INTRODUCTION}

Beginning in 2016 this is an early milestone in the implementation of the ASEAN Economic Community (MEA) or ASEAN Economic Community (AEC). One of the challenges faced by Indonesia as one of the countries that signed the agreement is the tight competition in terms of trade in goods and services. This requires a standardization of products and services that will open a broader market in the ASEAN region. Assurance of the quality of a product one of which can be done through chemical testing. Therefore, the competent personnel, especially in chemical testing, become one of the contributors in product quality control. In addition to opening up trade flows of products and services, the consequence of MEA implementation that must also be accepted is the opening of the professional labor market. This requires the existence of an Indonesian National Work Competency Standard (SKKNI) as a reference of personnel competence for certain field of work or profession so that it will increase competitiveness in ASEAN single market.

The $1^{\text {st }}$ Party Certification Institute (LSP P1) becomes an institution that plays an important role in facing current MEA challenges. Educational institutions that already have LSP P1 will contribute to the birth of competent human resources as outlined in the certification scheme in accordance with their respective fields of work. Therefore, the alignment between learning achievement and certification scheme becomes a necessity.

The curriculum of Diploma (D3) is designed with $60 \%$ practice and $40 \%$ theory so that skill or skill is strongly emphasized. Nevertheless, the competence according to Level $5 \mathrm{KKNI}$ will not be achieved without the foundation of a strong understanding of the concept. One of the capabilities that must be possessed by the graduate of Diploma (D3) is to master the theoretical concepts of certain knowledge areas in general, and able to formulate the solution of procedural problems. These competencies will support other competencies in terms of completing wide-ranging work, selecting appropriate methods from various options that have been or have not been standardized by analyzing the data, and able to demonstrate performance with quality and quantity measurable. 
Inorganic chemistry is part of the chemistry that studies the properties and reactions of inorganic compounds. Some sub-topics in this course include atomic structure, chemical bond, acid-base, element chemistry, complex compound and core chemistry. Much of the subject in Inorganic Chemistry is a very abstract material, especially in the materials of the Atomic Structure and the Chemical Association. This makes it difficult for students to understand the material if without using media that can describe the abstract material. The presentation of abstract material using two-dimensional or three-dimensional images or illustrations has not been able to provide a strong understanding by the students. Therefore, more real media or visual aids are needed to improve students' understanding.

Input of Diploma of Analytical Chemistry ideally derived from alumni of vocational school with a similar field of science. But until now ideal conditions cannot be achieved so that student input becomes very varied with a wide range. Based on the description and problems that have been submitted before it needed an improvement and innovation to ensure the achievement of learning outcomes and improvements in student achievement in the course of Inorganic Chemistry. The strategy chosen in this research is Student Centered Learning (SCL) strategy with Student Teams-Achievement Divisions (STAD) cooperative learning approach using integrated module worksheet and visuals especially on atom structure material and chemical bond.

Cooperative learning methods include several stages: tutorial, group work, and evaluation. In the tutorial stage, the lecturer divides the group and explains how cooperative learning strategies are implemented. The division of the group becomes an important beginning because the composition of students with the ability that varies must be considered. Therefore a baseline is needed to see the student's ability. The tutorial stage also provides an opportunity for lecturers to briefly present the material and provide stimulants for students to explore further. The next stage is group work. In this group work, the students are given the flexibility to discuss and solve problems by utilizing various sources. Cooperation among group members becomes an important factor for the achievement of learning objectives. Students with more ability to share with other students so it is expected at the end of the lecture all students have the same ability or almost the same. The last stage is a useful evaluation to assess the effectiveness of applied learning methods and to assess student achievement. This evaluation is particularly important to see if the cooperative method is really well implemented by the students.

Based on the above description, it can be formulated two problems as is:

What factors affect the successful application of STAD type cooperative learning in the course of Inorganic Chemistry?

How is the influence of application of STAD type cooperative learning on inorganic chemistry course to student learning motivation?

How is the effect of using integrated module worksheet and props molymod on Inorganic Chemistry course on student learning motivation?

How do student learning outcomes apply STAD type cooperative learning with the help of integrated module worksheet and molymod props?

\section{LITERATURE REVIEW}

\section{Cooperative Learning}

According to Sardiman, cooperative has a sense of cooperation in achieving common goals. Cooperative learning is a strategy used for the learning process, where learners will more easily find comprehensively the difficult concepts if they discuss it with other students about the problems encountered. In cooperative learning methods, learners are divided into small, heterogeneous groups that work together to achieve certain academic tasks [1].

Cooperative learning method has several types one of them is Student Teams-Achievement Divisions (STAD). Cooperative learning with the STAD model puts students in study groups of four or five students who have different academic skills so that in each group there are high, moderate, and low-achieving students or variations of gender, racial and ethnic groups, or another social group [2]. Still, according to Asma the stages of STAD type cooperative learning methods are as follows [2]:

Preparation of learning

Presentation of the material

Learning groups

Test

Determination of individual improvement scores

Group awards 
This cooperative learning model has been successfully applied to improve learning achievement among learners is on the subject of Inorganic Chemistry I in Chemistry Department UNIMED. A total of $87.87 \%$ of students successfully graduate in the course [3]. Besides, there was an increase of students' understanding on the subject of Inorganic Chemistry II after applied cooperative e-learning method in Chemical Education Department of UNY [4].

STAD type cooperative learning model has advantages compared to other learning models. According to Slavin, STAD type cooperative learning model is as follows [5]:

Each student has an opportunity to contribute substantially to his group, and the position of group members is equal

Promote interaction actively and positively and team member cooperation for the better

Helping students to gain more cross-racial friendship relationships

Some advantages STAD type cooperative learning model also mentioned by Rusman as is [6]:

Students have two forms of learning responsibility that is learning for themselves and helping fellow group members to learn

Students learn from each other or lessons by peers (peer teaching) is more effective than learning by lecturers

STAD type cooperative learning model can reduce the individualistic nature of students

Another advantage of the STAD type of cooperative learning model is to train students in developing social skills in addition to cognitive skills, the role of lecturers become more active and focused as facilitators, mediators, motivators, and evaluators [7]. Application of STAD cooperative learning model will also make the competition in the class become more alive, achievement and good learning result can be achieved by all group members, the quiz makes the students more motivated, students with low academic ability will be motivated to learn both individually and learn between fellow friends in the group so that the value of the group is not low, and the appreciation of the lecturers increases the motivation of students to be active in learning.

\section{Use of Molymod Viewer}

The use of teaching aids in learning is one effort to improve students' understanding of a topic. According to Nasution, the purpose of the demonstration is to provide variations in the way of teaching and provide more reality so that the meaning is more tangible and more focused to achieve the learning objectives [7]. Another function of props is to arouse students' interest in learning activities and make the interaction between lecturers and students or students more fun.

Inorganic Chemistry course contains topics that are very abstract especially related to the topic of Chemical Bonding. This topic discusses the various types of chemical bonds and the arrangement of atoms in a molecule. Such abstract topics can be explained by using the visualization of two-dimensional images. The use of two-dimensional images still has a weakness that students must have the ability to imagine or visualize the images. Therefore it takes props that can make the image become more real, that is the molymod props. Molymod props are props to describe the shape of a molecule. It consists of spheres of various sizes and colors representing atoms and rods representing bonds between atoms. The molymod can be disassembled according to the desired molecular shape.

\section{RESEARCH METHODS}

\section{Research Subject}

This research was conducted on the students of Diploma of Analytical Chemistry Force 2015 who took the course of Inorganic Chemistry in Semester Evenly 2015/2016 with the number of students 68 people.

\section{Research Procedure}

Planning

The planned action is divided into two cycles for one semester each cycle consisting of eight meetings including an exam. Some devices are prepared like CO-SAP, modules, worksheets, log book, props, exam questions, documentation tools and rewards.

Implementation of Action

Implementation of action in the first cycle is as follows:

1. Students in small groups undertake group learning conducted using modules and worksheets. Discussion activities are recorded in the logbook. Students work on the worksheets in accordance with their own understanding of learning outcomes with module sources and other resources they can get through textbooks and the internet. 
2. Presentation of materials by lecturers. The presentation of materials by the lecturer is to confirm the material that has been studied and worksheets that have been done by the students. At this stage, the lecturer also provides the next worksheet as material for the exercise.

3. The lecturer corrects the student worksheet and provides feedback to be delivered at the next meeting.

4. Stages a through $\mathrm{c}$ are repeated until the 7 th meeting

5. At the 8th meeting, an evaluation of student learning outcomes was done through the giving of the quiz. Quizzes are done independently (not groups) and conditioned like real tests. The question tested on the quiz is a collection of questions on the worksheet the previous student had worked on.

6. Evaluate quiz results to determine individual student improvements to be included in group scores. Through this evaluation, each student in the group contributed to the group score.

7. Awards

8. At this stage, the group with the highest development score will get the award.

Reflection

In the reflection phase, the researcher discusses with the students about the learning method that has been applied in cycle I. The advantages, constraints, and inputs from the students become the evaluation material for the next cycle.

\section{Assessment Instruments}

The instrument form used in this research are:

1. Worksheet

2. Worksheets are used to view student progress in any meeting or sub-material

3. Test

4. The test is conducted to determine the value of individual student learning outcomes done twice in every cycle, namely quiz and mid or late semester examination

5. Questionnaire

6. Questionnaires were used to assess students' attitudes toward STAD strategies and molymod props used in inorganic chemistry courses and to determine their effect on material comprehension.

\section{Data Processing}

Worksheets and tests are judged according to scores (weights) on each question. Group development is assessed by the following criteria:

TABLE 1. Assessment criteria for group members

\begin{tabular}{cc} 
Criteria & Score \\
\hline$>10$ under the target & 5 \\
10-1 below target & 10 \\
$1-10$ above target & 20 \\
11-20 above target & 30 \\
\hline
\end{tabular}

With the target, the score is 70 . From the score of each student in the group then used to calculate the group development score that is:

$$
\mathrm{N}=\frac{\text { total number of member development scores }}{\text { number of members }}
$$

The final score for determining student passing is calculated by combining the value of worksheets, quizzes, midterm and final examination. The target of the application of STAD type learning strategy in this Inorganic Chemistry course is the number of students who get the minimum B value of $60 \%$ (with baseline using the previous year data is $42 \%$ ). 


\section{RESULTS AND DISCUSSION}

Planning and Preparation of Learning

Inorganic Chemistry Learning through STAD type cooperative alignment is planned through two cycles i.e. cycle 1 (before midterm) and cycle 2 (after midterm). Some tools are prepared to support such learning: Course Outline-Unit of Recovery Events (CO-SAP), modules and worksheets and props of Molymod. It also prepared the assessment instrument that is about midterm, final examination and student questionnaires to measure student attitudes toward applied learning strategy. The lecture module contains lecture materials that are equipped with practice questions as one of the learning resources and student discussion materials. The use of the module aims to create a more lively, focused group discussion atmosphere and concentrate on the module's materials so that ultimately it will increase SAP's achievement and learning outcomes. The modules were previously validated first by experts in the field of Inorganic Chemistry whose results are presented in Table 2.

TABLE 2. Lecture module validation results

\begin{tabular}{cc} 
Criteria & Score \\
\hline Eligibility of content & 4.5 \\
Language & 4.5 \\
Channel & 4.3 \\
Average & 4.44
\end{tabular}

Table 2. shows the module validation results from experts with assessment criteria covering content feasibility, language, and graphics having an average grade of 4.44 (scale 1-5). Among the three criteria, the input points are related to the contents of the module which should present the relevance of each material to the field of chemical analysis. This input is used to fine-tune the module. However, not all materials can be attributed directly to the field of chemical analysis. The materials that can be attributed are chemical equilibrium, solubility equilibrium, and complex compounds.

Preparation is also done to the research subjects of the second-semester students. To create groups with varied members, a baseline is needed to see students' academic abilities. This baseline is taken from the odd semester course value which has relevance to Inorganic Chemistry is Chemical Analysis and Basic Chemistry. A total of 68 students were grouped into 16 groups

\section{Implementation of Learning through STAD Type Cooperative Learning}

The learning design consists of two cycles of implementation details in the first cycle are as follows:

1. Students in small groups undertake group learning conducted using modules and worksheets. Discussion activities are recorded in the logbook. Students work on the worksheets in accordance with their own understanding of learning outcomes with module sources and other resources they can get through textbooks and the internet.

2. Presentation of materials by lecturers. The presentation of materials by the lecturer is to confirm the material that has been studied and worksheets that have been done by the students. At this stage, the lecturer also provides the next worksheet as material for the exercise.

3. The lecturer corrects the student worksheet and provides feedback to be delivered at the next meeting.

4. Stages a through $\mathrm{c}$ are repeated until the 7 th meeting

5. At the 8th meeting, an evaluation of student learning outcomes was done through the giving of the quiz. Quizzes are done independently (not groups) and conditioned like real tests. The question tested on the quiz is a collection of questions on the worksheet the previous student had worked on.

6. Evaluate quiz results to determine individual student improvements to be included in group scores. Through this evaluation, each student in the group contributed to the group score.

7. Awards

8. At this stage, the group with the highest development score will get the award 


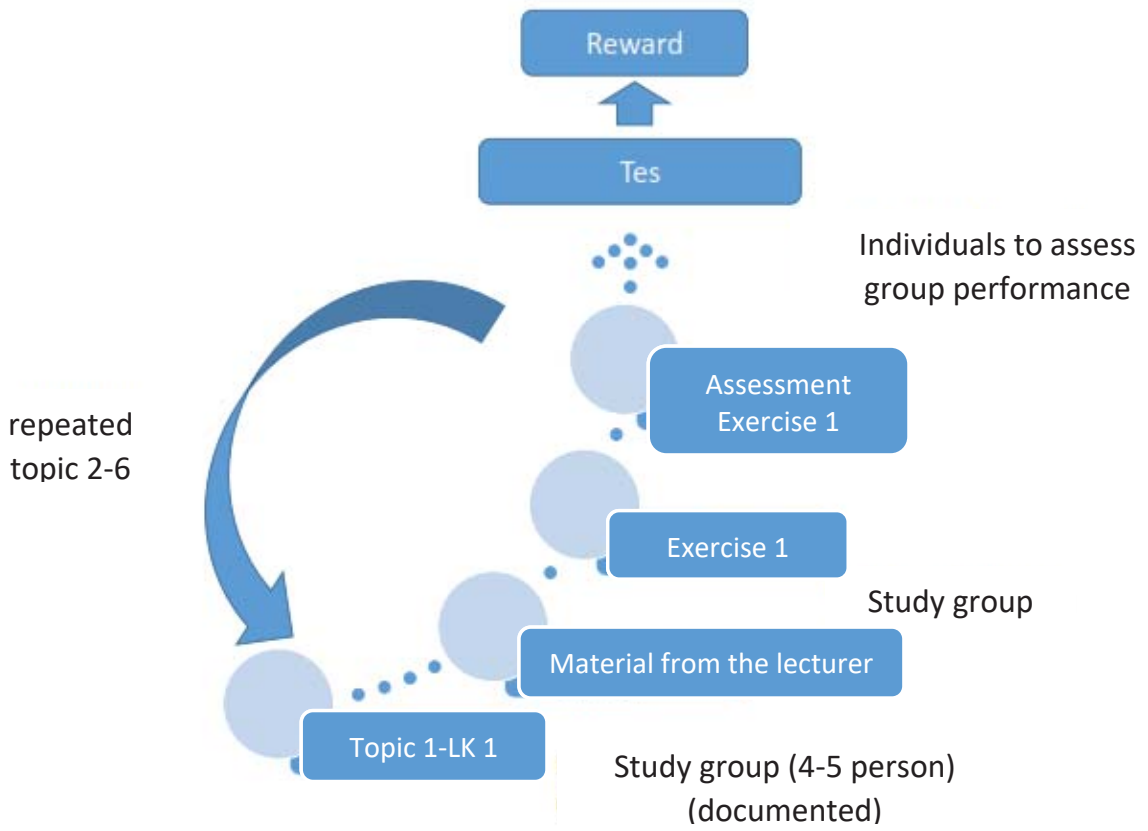

FIGURE 1. Learning cycle with STAD strategy

\section{Evaluation of Results}

This research was conducted to improve student learning outcomes in the course of Inorganic Chemistry. The cooperative strategy with the STAD approach was chosen because the research subjects had varied backgrounds. Through STAD strategy students work together in solving problems through group discussion. In the discussion group is expected to occur sharing knowledge or information and also generate motivation to learn among fellow students. STAD strategy applied is also combined with the use of props Molymod as a tool in understanding the abstract material, especially chemical bonds and molecular geometry. Each group will then see its progress and achievement on the target set through the worksheet given on each material that is as much as 9 worksheets and through the quiz held twice. The sheet material is shown in Table 3.

TABLE 3. Material and type of student worksheet

\begin{tabular}{ccc}
\hline No & Material & Types of Problems \\
\hline 1 & The Development of Atomic Theory & Multiple choice \\
2 & Modern Atomic Theory & Multiple choice \\
3 & Elements Periodic System and Properties & Multiple choice \\
4 & Chemical Association & Multiple choice \\
5 & Molecular Geometry & Multiple choice \\
6 & Chemical equilibrium & Multiple Choice and Essay \\
7 & Solubility Equilibrium & Essays \\
8 & Chemical Coordination & Multiple Choices and Essays \\
9 & The Binding Theory of Complex & Multiple Choices and Essays \\
\hline
\end{tabular}

Group performance is assessed using criteria in Table 1. for each worksheet. Assessment of group progress is also done on the quiz. The workgroup is done in groups while the quiz is done independently. The results of the development of the group are shown in Table 4. and Figure 2. 
TABLE 4. Scores of group progress for each worksheet

\begin{tabular}{cccccccccc}
\hline Group & \multicolumn{7}{c}{ LK } & \multicolumn{7}{c}{ Worksheet } \\
\cline { 2 - 10 } & LK 1 & LK 2 & LK 3 & LK 4 & LK 5 & LK 6 & LK 7 & LK 8 & LK 9 \\
\hline KLP 1 & 22,5 & 163 & 250 & 213 & 300 & 27.5 & 250 & 22,5 & 300 \\
KLP 2 & 100 & 17.5 & 17.5 & 163 & 300 & 22,5 & 200 & 250 & 200 \\
KLP 3 & 150 & 13,8 & 17,5 & 250 & 22,5 & 300 & 27,5 & 27,5 & 300 \\
KLP 4 & 17,5 & 300 & 250 & 300 & 300 & 300 & 250 & 250 & 27,5 \\
KLP 5 & 12,5 & 250 & 200 & 250 & 27,5 & 250 & 250 & 200 & 22,5 \\
KLP 6 & 160 & 210 & 240 & 280 & 220 & 260 & 280 & 240 & 280 \\
KLP 7 & 100 & 110 & 23,8 & 27,5 & 22,5 & 27,5 & 250 & 27,5 & 250 \\
KLP 8 & 19,2 & 11,7 & 283 & 300 & 300 & 26,7 & 26,7 & 283 & 26,7 \\
KLP 9 & 80 & 140 & 70 & 150 & 250 & 200 & 240 & 240 & 280 \\
KLP 10 & 150 & 213 & 22,5 & 150 & 27,5 & 250 & 27,5 & 27,5 & 300 \\
KLP 11 & 213 & 200 & 150 & 12,5 & 22,5 & 27,5 & 27,5 & 27,5 & 27,5 \\
KLP 12 & 6,3 & 6,3 & 100 & 150 & 300 & 22,5 & 250 & 22,5 & 27,5 \\
KLP 13 & 100 & 22,5 & 163 & 12,5 & 27,5 & 250 & 300 & 300 & 300 \\
KLP 14 & 8,8 & 17,5 & 200 & 100 & 27,5 & 27,5 & 27,5 & 300 & 27,5 \\
KLP 15 & 100 & 200 & 13,8 & 13,8 & 300 & 27,5 & 27,5 & 300 & 27,5 \\
KLP 16 & 7,5 & 12,5 & 17,5 & 17,5 & 27,5 & 250 & 27,5 & 300 & 27,5 \\
Average & 13.1 & 17.5 & 18.9 & 19.6 & 27.0 & 25.9 & 26.2 & 26.3 & 27.2 \\
\hline
\end{tabular}

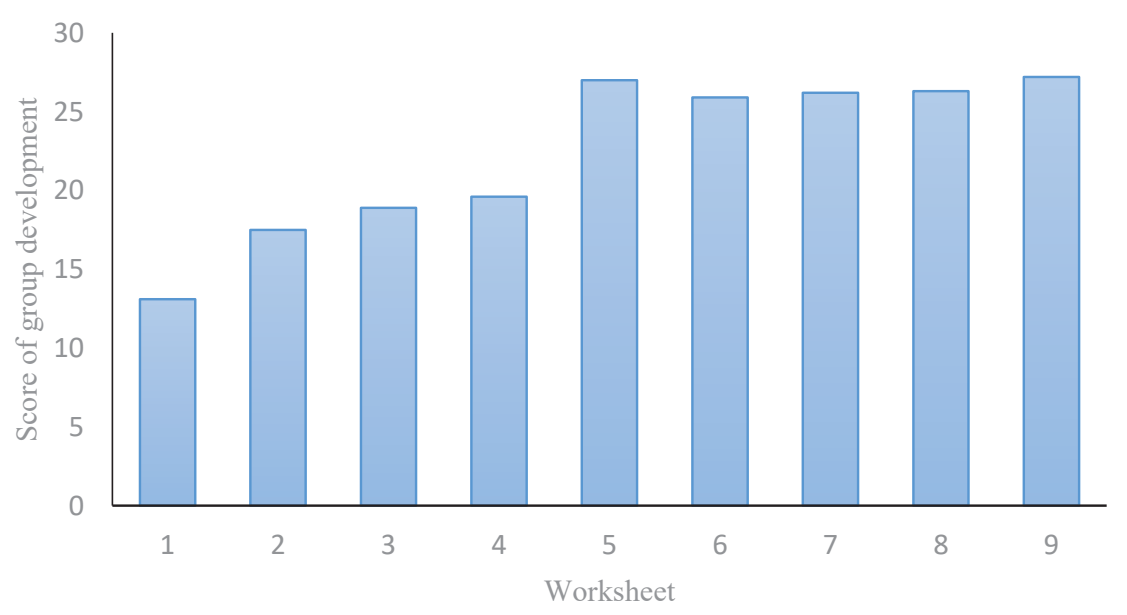

FIGURE 2. Tendency of group development score

From Figure 2., it can be seen that all groups showed an increasing trend of the score from Worksheet 1 (LK1) to Worksheet 9 (LK9). A low score on the initial worksheet given at the beginning of the meeting indicates that the student has not found a proper learning strategy in the STAD type cooperative learning method. This tendency is seen in LK1-LK4 on the developmental materials of atomic theory, modern atomic theory, the system and periodic nature of elements, and chemical bonds. These materials are a very basic and humble concept. 
From Figure 2. it is also seen that almost all groups showed a significant increase in group development in LK5. This is because besides students have found learning strategies with STAD type cooperative method, the LK5 students also use props in the form of Molymod is a molecular model to study the shape of molecular geometry. With this Molymod students can arrange the form of molecules in three dimensions are done in groups as well. Abstract material that can be more easily understood by using his props. The group development value measured from the quiz score is shown in Table 5.

In LK6-LK9 the average value of group development tends to be high and stable. This can be due to the fact that the material in this cycle is more calculated with fewer fundamental concepts. From this tendency can be concluded that students are better able to do scientific sharing for the material that is a count compared to the material that is the basic concepts. So STAD type cooperative learning strategy is suitable for counting material.

Table 5. The value of group development is measured from the quiz score

\begin{tabular}{cccc}
\hline Group & On average LK & Quiz 1 & Quiz 2 \\
\hline KLP 1 & 24,4 & 12,5 & 11,25 \\
KLP 2 & 19,9 & 6,25 & 5 \\
KLP 3 & 23,2 & 10 & 5 \\
KLP 4 & 26,7 & 5 & 12,5 \\
KLP 5 & 22,5 & 7,5 & 5 \\
KLP 6 & 241 & 11 & 13 \\
KLP 7 & 22,2 & 6,25 & 8,75 \\
KLP 8 & 253 & 12,5 & 13 \\
KLP 9 & 183 & 12 & 14 \\
KLP 10 & 23,5 & 12,5 & 18,75 \\
KLP 11 & 22,4 & 10 & 5 \\
KLP 12 & 183 & 6,25 & 8,75 \\
KLP 13 & 226 & 11,25 & 8,75 \\
KLP 14 & 21,8 & 6,25 & 7,5 \\
KLP 15 & 22,2 & 12,5 & 18,75 \\
KLP 16 & 21,4 & 6,67 & 13,33 \\
\hline
\end{tabular}

From Table 5. it can be seen that there is a very drastic decline in the value of group development as measured through worksheets and quizzes with the same problem. This is because processing is done outside the classroom and can be done in groups while at the time of student quiz work individually with the conditioned atmosphere like the test with seat arranged and supervised by supervisor. The data indicates that the student is still very dependent on the other group members in working on the worksheet so that the material absorption is still low. This can be seen from the much different scores between LK and quiz with the same problem.

LK score and quiz are then combined with the assessment of the Middle Exam Semester and Final Exam Semester so that will get the final value that will determine the graduation of students on the Inorganic Chemistry Courses. From the result of data processing student value, as much as $50 \%$ of students get $B$ value after applying STAD type cooperative learning strategy. This value increased compared to the previous value of $42 \%$, but still below the target achievement of $60 \%$.

In addition to using the test, evaluation of the applied learning strategy is also done by using questionnaires to assess student attitudes toward STAD learning methods and the use of props Molymod [9]. The results of students' attitude assessment are shown in Table 6. The influence of student attitudes toward STAD strategy and Molymod props on material understanding is shown in Figure 3. and Figure 4. 
TABLE 6. Assessment of student attitudes toward STERN strategy and Molymod usage

\begin{tabular}{cc}
\hline Parameter & $\begin{array}{c}\text { Achievements } \\
(\%)\end{array}$ \\
\hline $\begin{array}{c}\text { Attitudes towards the application of STAD } \\
\text { Material understanding through STAD } \\
\text { strategy }\end{array}$ & 80 \\
Attitude towards the use of Molymod & 65.5 \\
Understanding of matter through the use of \\
Molymod
\end{tabular}

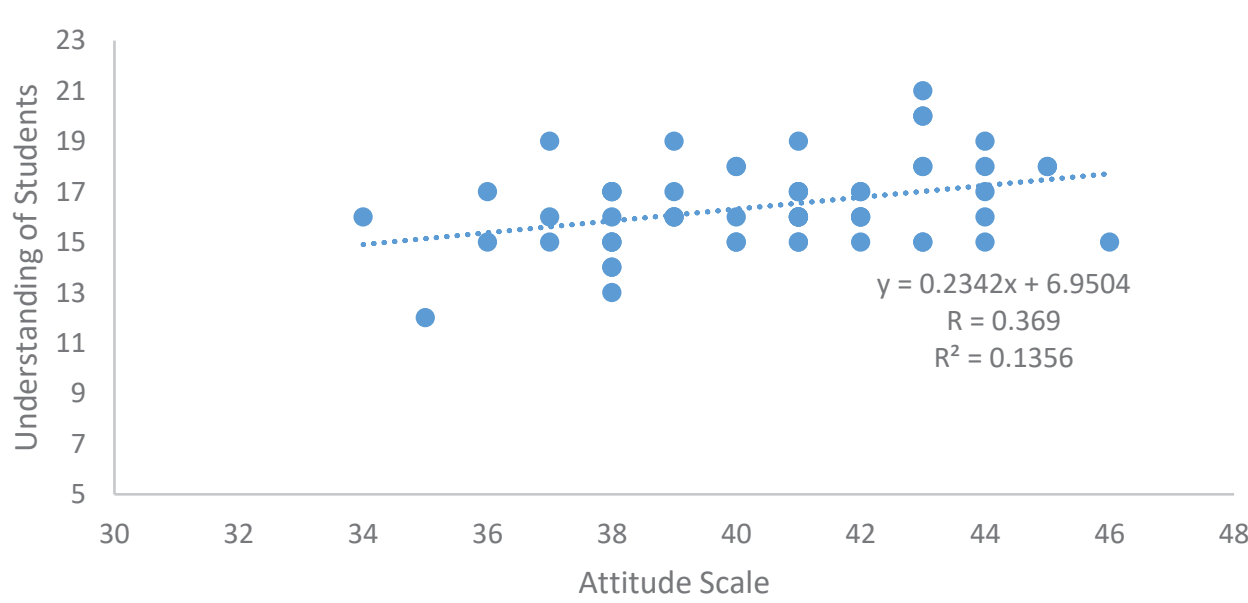

FIGURE 3. Influence of student attitude toward STAD strategy with material understanding

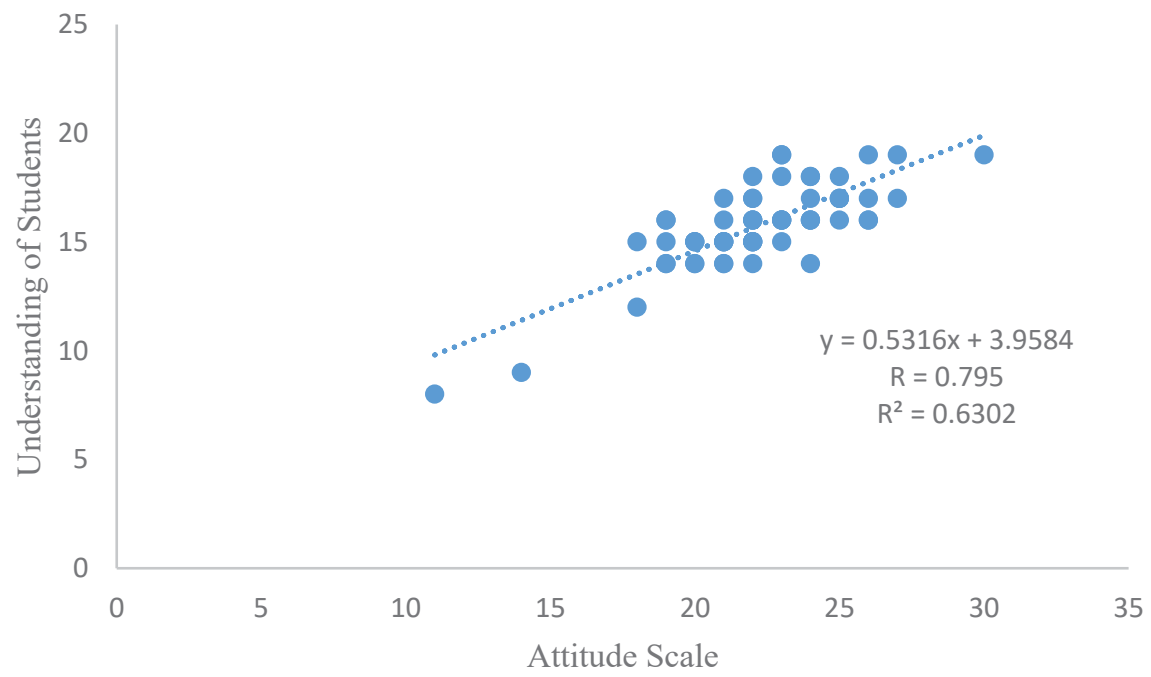

FIGURE 4. Influence of student attitudes toward the use of Molymod props against material understanding

From Table 6. and Figure 3. it can be concluded that there is no influence on students' attitudes with the material understanding that can be seen from the achievement of material understanding by using STAD 
strategy only $65,5 \%$ and also seen from the very low coefficient of determination is 0,1356 . On the contrary, from Figure 4. can be seen the strong enough influence between student's attitude toward molymod usage with material understanding especially chemical bond and molecular geometry shape shown from the coefficient of determination value is 0,6302 .

The attitude evaluation questionnaire distributed to the students is also accompanied by filling column to explore the attitude, impressions, and opinions of students on the learning strategy that has been applied. The results of the contents can then be summarized as follows:

1. STAD Strategy helps students to be ready for the lecture through discussions with friends first and motivated to learn independently

2. With STAD students more easily understand the material when the lecturer explains in class

3. Molymod props make learning more interesting and material easier to understand

4. Students have difficulty scheduling discussion time

5. The lecturer can not monitor the discussion

6. There are group members who still rely on the value of other members

7. Less motivated to explore the material through other sources so the discussion is stuck

8. There are groups that have not been able to create a comfortable atmosphere among its members

From the results of reflection, it can be concluded that STAD strategy can actually help students to prepare themselves in the classroom. Similarly, the use of molymod props that make the abstract material more easily understood [10]. However, the success of STAD strategy is highly dependent on the availability of time for discussion and conducive environmental conditions. Lecturers also have to play a more special role, especially during discussions to monitor and motivate students so that discussions can run more effectively.

\section{CONCLUSION}

1. Factors that influence the successful application of STAD type cooperative learning are the availability of tools such as modules and worksheets, the availability of discussion time and access to other learning resources, as well as the role of the lecturer as facilitator and motivator.

2. Application of STAD type cooperative learning in Inorganic Chemistry course resulted in achievement of learning motivation by $80 \%$. However, the students' attitude toward STAD strategy has no effect on the understanding of Inorganic Chemical material

3. The use of props Molymod in Inorganic Chemistry resulted in achievement of learning motivation of $78.8 \%$. Students' attitudes influence the understanding of matter, especially the shape of molecular geometry.

4. STAD type cooperative learning strategy in the course of Inorganic Chemistry is suitable for material that is calculated compared to the basic concept material.

\section{ACKNOWLEDGMENTS}

The authors would like to thank the Academic Development Board (BPA) of the Islamic University of Indonesia who have contributed funds to this research through Regular Teaching Grants Even Semester $2015 / 2016$

\section{REFERENCES}

1. A. M. Sardiman, Interaksi dan Motivasi Belajar (Rajawali Pers, Jakarta, 2011).

2. N. Asma, Model Pembelajaran Kooperatif (Depdiknas, Jakarta, 2008).

3. L. Simatupang and R.S Dewi, JPK, 6, 1, (2014).

4. M. P Utomo, E. Widjajanti, and A. K. Prodjosantoso, in: Prosiding Seminar Nasional Penelitian, Pendidikan, dan Penerapan MIPA UNY, (FMIPA UNY, Yogyakarta, 2011).

5. R. E. Slavin, Cooperative Learning Teori, Riset dan Praktik (Nusa Media, Bandung, 2010).

6. Rusman, Model-Model Pembelajaran Mengembangkan Profesionalisme Guru (PT Raja Grafindo Persada, Jakarta, 2011).

7. Isjoni, Alfabeta, 3, 96-104 (2010).

8. S. Nasution, Dasar-dasar Kurikulum (Bumi Aksara, Jakarta, 2008). 
9. R. Laura, Ph.D. thesis, Dublin City University, 2016.

10. M. Setyarini, Liliasari, A. Kadarohman, and M. A. Martoprawiro, Cakrawala Pendidikan 36, 1, 91-101 (2017). 